\title{
THE ROLE OF THE ANAESTHETIST IN/A DIAGNOSTIC MYASTHENIA GRAVIS CLINIC
}

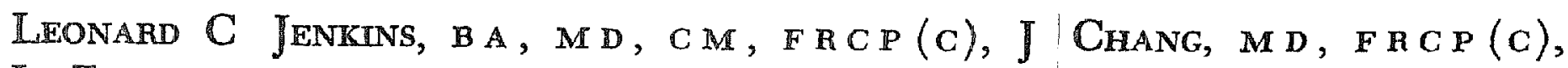
L Zeldowicz, MD, W J BuCKLER, MD, AND $\mathbb{H}$ B, Graves, B A, M D, C $\mathbf{M}$, $\mathbb{F} \mathbb{R} P(C)$

\section{INTRODUCTION}

THE RESULTS OF modern research have led to a general acceptance of the theory that the abnormality in myasthenia gravis is at the neuromuscular junction

Churchill-Davidson and Richardson, ${ }^{1}$ using a combination of drugs and electromyographic technique, in patients with myasthenia gravis, found evidence of a general alteration in the response of their motor end-plates throughout the body, even in clinically unaffected muscles They suggested that although acetylcholne was produced in a normal manner in myasthenic patients, the end-plate responded to 1 , or one of its breakdown products, in a different manner than in normal muscle Since then Grob, ${ }^{2}$ using intra-arterial injections of acetylcholine, found that the end-plate of myasthenic patients also responded differently to choline, a normal breakdown product of acetylcholine, compared with normal muscle It was found that there was first a paralysis due to this injected acetylcholine, followed by recovery This was then followed rapidly by a secondary phase of prolonged paralysis thought to be due to choline In the myasthenia gravis patient this second phase of paralysis was reversible by neostigmine, whereas in normal muscle, administration of neostigmine in the second phase produces a further decrease in muscle strength and a further drop in electromyographic potential

The present concept of myasthenia gravis is therefore an alteration in the response of the motor end-plate, so that acetylcholne no longer only produces a short-lived depolarization but also leads to a competinve block

Mild cases of myasthenia gravis present a difficult problem of diagnosis It is hardly surprising, therefore, that many drugs have been used at one tume or another as tests for the presence of this condition

Both neostigmine and edrophonium have been widely used in tests for the presence of myasthenia gravis Both drugs act by inhibiting the action of cholnesterase and by direct depolanzation at the motor end-plate In myasthenia gravis the action of both these drugs is to improve muscle power Edrophonium, by virtue of its short duration of action (one to two minutes) and minimal muscarinic side-effects, can be given intravenously (10 mg) and has now largely replaced neostigmine as a diagnostic agent

Bennett and Cash $^{3}$ were among the first to suggest the use of $d$-tubocurare as a test for the presence of myasthenia gravis They pointed out that myasthemic

* From the Departments of Anaesthesia, Neurology, and Physical Medicine, Vancouver General Hospital, and the University of British Columbia, Faculty of Medicine, Vancouver, $B$ C 
patients show an increased sensitivity to this drug so that doses varying from $1 / 5$ th to $1 / 100^{\text {th }}$ of the normal are capable of producing profound weakness The "curare test" for the presence of myasthenia gravis has now become widely accepted, but it has limitations For instance, only the clinically affected muscles of a patient with myasthenia gravis show this sensitivity The most sensitive muscles are those that already give evidence of clinical weakness In contrast to the decamethonium test, which demonstrates a generalized change in the mild case of myasthenia gravis, the curare test may fall, and in the severe case may prove hazardous

Whereas the neostigmine and edrophonium tests are often equivocal, the decamethonium test has consistently demonstrated its definitive diagnostic value

\section{METHOD}

These studies have been conducted by physicians representing three disciplines neurology, physical medicine, and anaesthesiology The anaesthetist is an essential member of this team by virtue of his lnowledge of the pharmacology and physiology of the myoneural junction and his ability to manage possible ventilatory madequacy, which may develop in these patients during the test In addition, he is able to provide a continuty of care when a patient from the clinic is referred for thymectomy or other surgical procedures

This method of electromyographic diagnosis for myasthenıa gravis is a modification of the one used by Churchill-Davidson and Richardson ${ }^{14}$ The patient is placed supine on a table with an intravenous infusion running in his forearm A dilute solution of decamethonium (30 mg in $12 \mathrm{ml}$ ) is prepared for injection Surface recording electrodes are placed over the thenar muscles whether clinically affected or not and the median nerve is then stımulated at the wrist with a supramaximal square-wave stımulus of $01-\mathrm{msec}$ duration Stimuli are spaced at between 1 and 60 seconds apart The height (voltage) of the evoked action potential is observed on the oscilloscope and recorded on film The volitional power is studied by the measurement of the grip strength in the opposite hand using a rolled syphgmomanometer cuff initially inflated at $50 \mathrm{~mm} \mathrm{Hg}$, straight leg raising, and the range of extraocular muscle movements After the control readings are recorded, $10 \mathrm{mg}$ decamethonium $(40 \mathrm{ml})$ is injected intravenously followed by a further $05 \mathrm{mg}(20 \mathrm{ml})$ at the end of the second minute The action potentials and volitional power are measured periodically and recorded before and after each injection At the end of the fourth minute a further $05 \mathrm{mg}$ of decamethonium is injected if the grip strength is only slightly reduced Every two minutes the above procedures are repeated until the grip strength is decreased significantly from the original reading This usually precedes reduction of the action potential A total dose of 25 to $35 \mathrm{mg}$ decamethonium is given if there is only a slight decrease in volitional power If at any tume there is any difficulty in respiration, the administration of decamethonium is not repeated

In the second part of the test edrophonium $10 \mathrm{mg}$ is administered intravenously The edrophonium is injected when the action potential is stabilized, preferably 
at about 50 per cent of its original value Edrophonium rapidly reheves the decamethonium-induced paresis in the patients with myasthenia gravis, without further drop or with improvement in the action potential, whereas it increases the paresis in normal subjects, with a corresponding further drop in their evoked muscle action potential

\section{RESULTS}

The following results were obtamed from observations on 23 patients suspected of having myasthenia gravis and 14 normal (control) subjects Of the 23 suspected patients, 14 patients were confirmed as having myasthenia gravis

Following an intravenous injection $(10 \mathrm{mg})$ of decamethonium, normal conscious subjects (contıols) demonstrated an early, progressive decrease in extraocular muscle strength, then in hand-grip strength, and finally a corresponding drop in their evoked muscle action potential ( $\mathbb{F}_{1} \mathbf{1}$ ) All these values decieased further, following administration of ediophonium $10 \mathrm{mg}$ (Fig 1) When the two clinical measurements of hand-grip strength and extraocular muscle weakness were objectively considered to have retuined to pre-test performance, the action potential remamed subnormal ( $\left.F_{1} g 1\right)$, reflecting the patients' subjective feeling of weakness

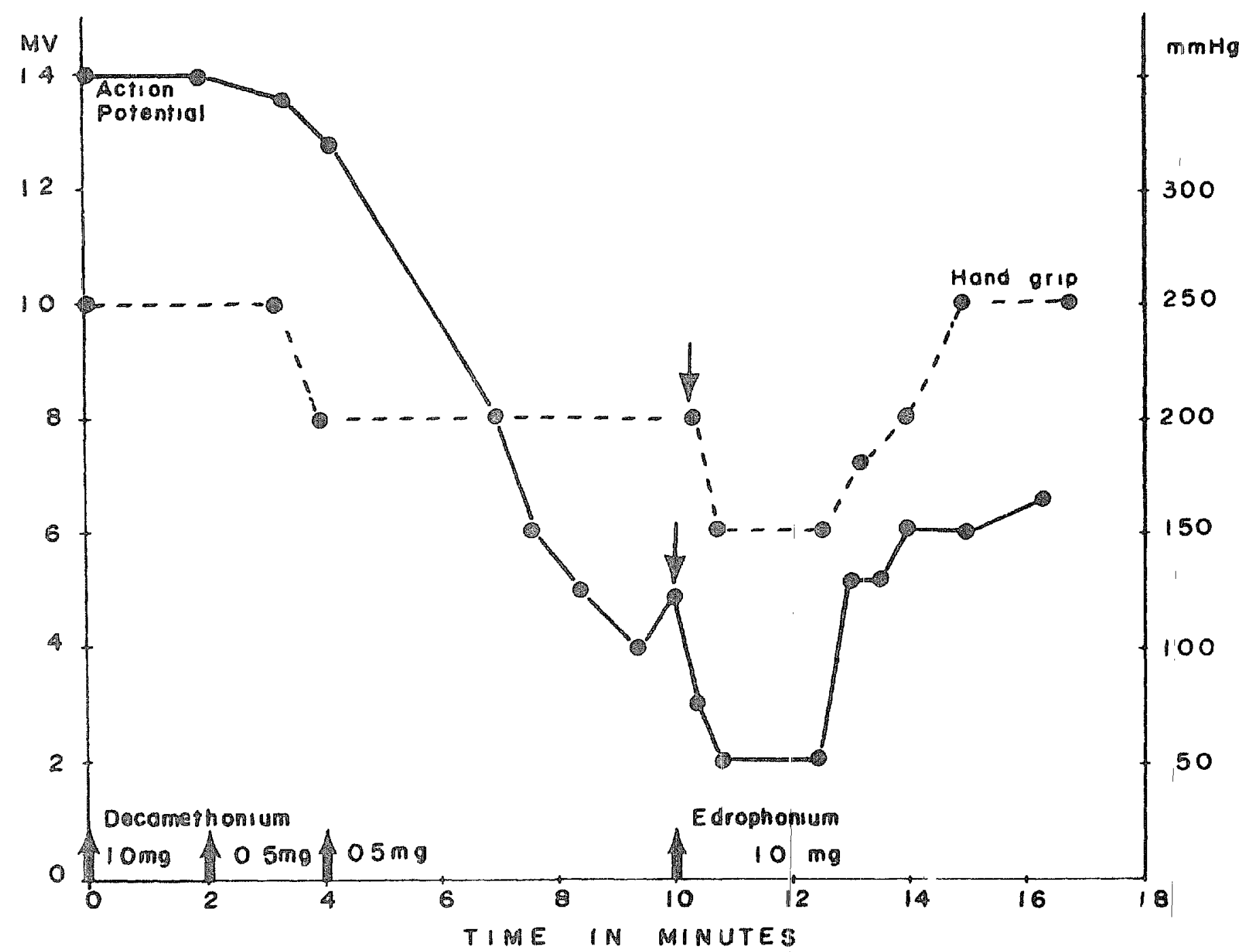

FIGURE 1 The course of electromyographic action potential and hand-grip strength in a normal subject ( $\mathrm{JAH}$ ) following decamethonium and edrophonium administration Note the lack of resistance in electromyographic action potentidl drop, and further decrease in the action potential following edrophonium administration 
PATIENT $\left(P_{0} P_{0}\right\rangle$

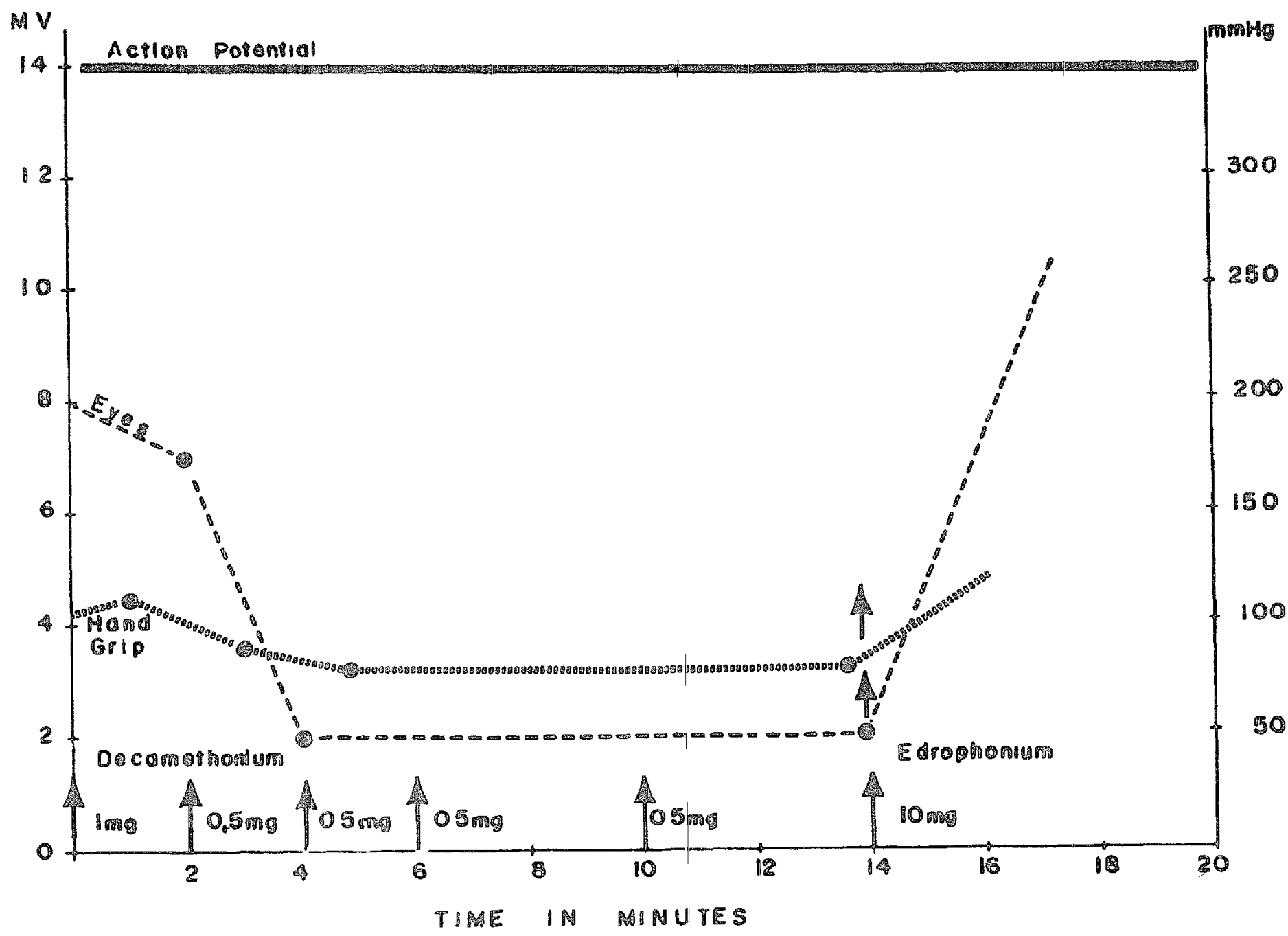

Figure 2 Course of electromyographic action potential, hand-grip strength, and eye signs in myasthenia gravis (ocular form) following decamethonium and edrophonium administration Note the marked resistance to change in electromyographic action potential following decamethonium administration In contrast to the normal subject's response (Fig 1 ), there is an increase in the hand-grip strength and extraocular muscle response following edrophonium administration

In contrast, myasthenia gravis patients demonstrated resistance to decamethonum, as measured by extraocular muscle strength, hand-grip strength, and evoked muscle action potental In fact, in the ocular forms of this disease the evoked muscle action potential may never alter, in spite of large doses of decamethonium, from the pre-test base-line reading ( $\left.\mathbb{F}_{1}{ }_{2} 2\right)$ With larger doses of decamethonium in the generalızed forms of myasthenia gravis, the evoked muscle action potential eventually decreased (Fig 3) In both forms (ocular and generalized) there was improvement in evoked muscle action potential, hand-grip strength, and extraocular muscle strength following the administration of edrophonium (Figs 2 and 3 )

\section{Discussion}

Decamethonum is believed to act in a manner similar to acetylcholine but has the advantage that it is not destroyed by cholnesterase ${ }^{5}$ Its use in a patient with myasthenia gravis is, therefore, of particular importance and has been descilbed fully by Churchil-Davidson and Ruchardson 1 In normal subjects the injection 


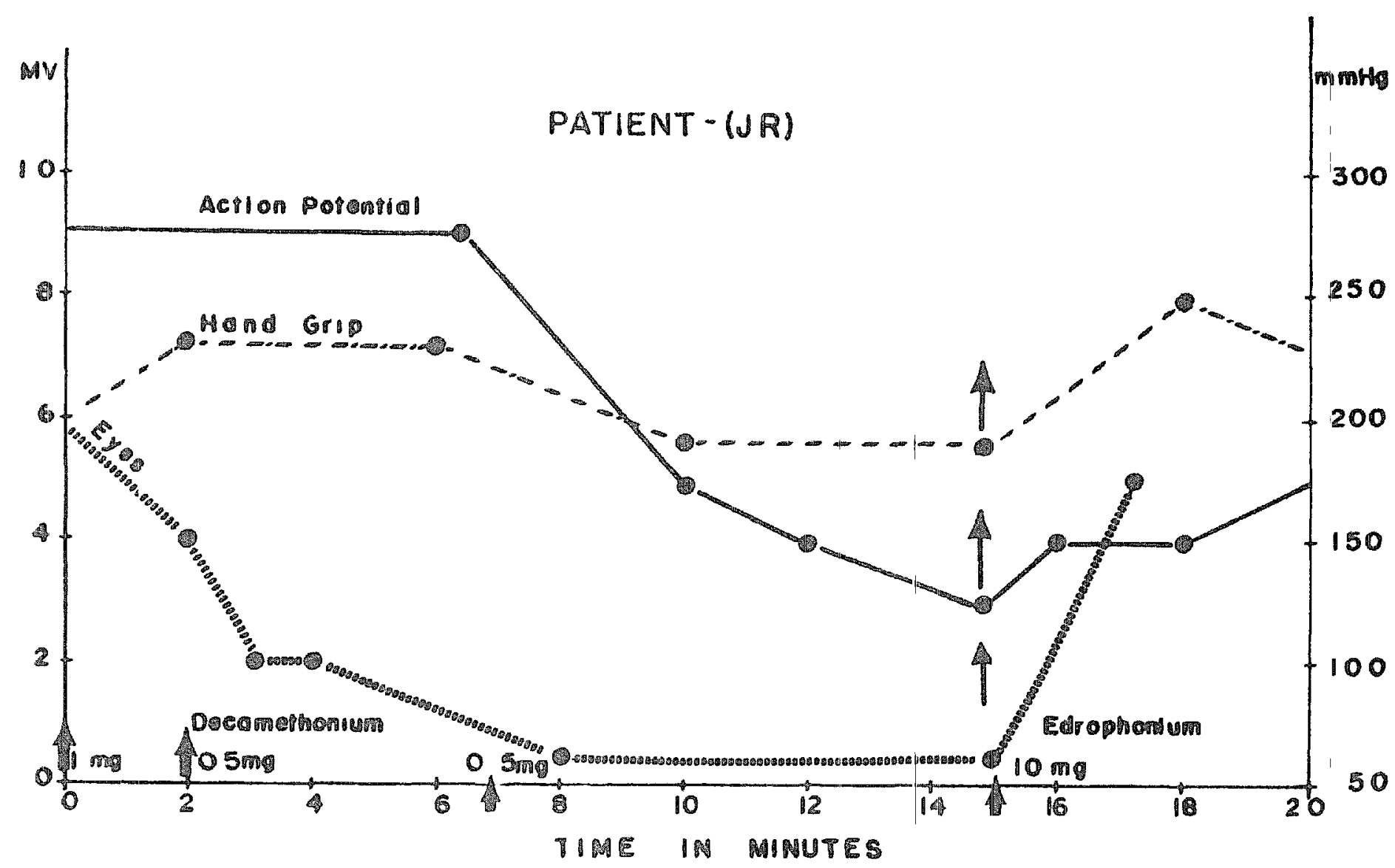

Figure 3 Course of electromyographic action potentıal, eye signs, and hand-grip strength in myasthenia gravis (generalized form, post-thymectomy) Note that there is not only resistance to drop in electromyographic action potential, following decamethonium administration, but also there is an actual initial increase in hand-gnp strength Again, there is improvement in electromyographic action potential, hand-grip stiength, and extraocular muscle activity following edrophonium administration

of decamethonium produces a neuromuscular block with all the signs and symptoms of depolarization In cases of myasthenıa gravis it shows evidence of a dual block (depolarization block followed by a lcompetitive block) In the clinically unaffected muscles in the myasthenia gravis patient there is marked resistance to decamethonium-induced muscle weakness and reduction of the corresponding evoked muscle action potential

The combination of electromyographic techniques with decamethonum and edrophonium has enabled the identification of three stages in the progression of myasthenia gravis muscle These three stages may coexist in dufferent muscles in the same patient

\section{Stage of Resistance}

In this stage the muscle shows no evidence of clinical weakness but the motor end-plate shows a remarkable tolerance to the depolarizing action of decamethonium Whereas in normal subjects a dose of 25 to $30 \mathrm{mg}$ is capable of producing profound paralysis, myasthenic muscle in the stage of resistance can tolerate doses three to four times as great before showing evidence of any weakness ${ }^{6}$ The fact that this resistance is so clearly shown in very mild cases of myasthenia gravis gives decamethonium superionity over "curaie" as a test in the diagnosis of myasthenia gravis We have commonly seen this stage in patients with the ocular forms of myasthenia gravis (Fig 2) 


\section{Stage of Dual Block}

The onset of this stage in a muscle is manifested by the appearance of clinical weakness Decamethonum, acting like a large dose of acetylcholne, eventually produces a competitive block, which is reversible by the injection of an anticholınesterase substance (edrophonıum) There may also be present some muscle fibres in a state of depolarizing block The simultaneous presence of muscle fibres in each type of block constitutes the dual block phenomenon ${ }^{6}$ In contrast, decamethonium in small doses in normal subjects leads to a depolanization type of neuromuscular block In larger or repeated doses a competitive block may be produced This would lend support to the theory that there is a more sensitive decamethonium competitive block effect in the patient with myasthenia gravis than in the normal subject If, now, an anticholinesterase drug is given to normal subjects, it produces summation of depolarization with increased weakness and a corresponding drop in the evoked muscle action potential

This is the most common form of myasthenia gravis, where anticholinesterase therapy is effective in controlling the condition

\section{Stage of Myopathy (or Refractoriness)}

After prolonged periods in which the rauscle fibre has not contracted, the muscle atrophies, and clinical wasting is evident This stage is seen clinically where increasing doses of anticholinesterases result in no further improvement in muscle strength

The evidence avarlable ${ }^{7}$ suggests that the natural history of the development of myasthenia gravis often goes through the stages in the order in which they have been discussed The severity of the disease depends on the number of muscle fibres blocked competitively If most of the fibres are merely in the resistant phase, then the condition is mild

Decamethonium, therefore, may be used advantageously as a test for the presence of myasthenıa gravis

\section{SUMmary}

A modified method of electromyographic diagnosis for myasthenia gravis using decamethonium is described The role of the anaesthetist in association with a neurologist and physiatrist in this myasthenia gravis diagnostic clinic 1s outlined

The combination of electromyographic techniques with decamethonium and edrophonium has enabled the identification of three stages in the progression of myasthenı gravis muscle (1) stage of resistance, (2) stage of dual block, (3) stage of myopathy ( refractormess)

In contrast to the decamethonium test, which enables the demonstration of a generalized change of neuromuscular transmission in the mild case of myasthenia gravis (the group of cases which present a difficult problem of diagnosis), the "curare" test may fall In the severe case the curare test may prove hazardous In addition, whereas the neostigmine and edrophonium tests are often equivocal, 
the decamethonium test has consistently demonstrated its definite diagnostic value Decamethonium, therefore, may be used advantageously as a test for the presence of myasthenıa gravis

\section{RÉSUMÉ}

Nous avons décrit une méthode modıfiée de diagnostic électromyographique de la myasthénıe grave en employant le décaméthonıum Nous avons tracé le rôle de l'anesthésıste qu se joint au neurologue et au psychıâtre pour établır le diagnostic clinique de la myasthénıe grave

L'association des techniques électromyographiqups avec l'adminıstration du décaméthonıum et de l'édrophonıum a rendu possible l'identification de trois différents degrés dans l'évolution de la myasthénıe musculare (1) degré de résistance, (2) degré de blocage double, (3) degré de myopathie

Par contraste avec le test du décaméthonium qui rend possible une illustrałion d'un changement généralısé de la transmission neuromuscularre dans les cas bénıns de myasthénie grave (c'est ce groupe de malades qui présentent un problème dıfficile de dragnostıc), le test au curare peut faillır à la tâche Dans les cas sérneux ou graves, le test au curare peut s'avérer risqué De plus, étant donné que les tests à la néostigmine et à l'édrophonıum sont souvent identiques, le test au décaméthonium a constamment démontré sa valeur diagnostique précise En conséquence, on peut se servir avec avantage du décaméthonium pour dépister la présence d'une myasthénie grave

\section{REFERENCES}

1 Churchill-Davidson, $\mathrm{H}$ C \& Richiardson, A $\mathbb{T}$ The Action of Decamethonium Iodide (C10) in Myasthenia Gravis J Neurol Psychiat 15129 (1952)

2 Grob, $D$, Johns, $\mathbb{R}$ J, \& Harvey, A M Alterations in Neusomuscular Transmissions in Myasthenia Gravis as Determined by Studies of Drug Action Am J Med 19684 (1955)

3 Bennet, A E \& Cash, $\mathbb{P} \mathbb{T}$ Myasthenia Gravis Curare Sensitivity New Diagnostic Test and Approach to Causation Arch Neurol Psychial. 49537 (1943)

4 Churchill-Davidson, H C \& Richardson, A $\mathrm{T}$ Decamethonium Iodide (C10) Some Observations on Its Action using Electromyography Proc Roy Soc Med 45179 (1952)

5 ZAIMIS, E J The Action of Decamethonium on Normal and Denervated Mammalian Muscle f Physiol (Lond) 112176 (1951)

6 Churchill-Davidoson, H $\mathbb{C}$ \& Richardson, A $T$ Neuromuscular Transmission in Myasthenıa Gravis J Physiol (Lond) 122252 (1953)

7 Foldes, F F \& MCNall, P G Myasthemia Gravis A Guide for Anaesthesiologists Anesthesiology $23 \quad 837-872$ (1962) 